\title{
Effect of Cocoa (Theobroma cacao) Plantation Types on the Distribution of Anuran Communities in Ore, Ondo State, Nigeria
}

\section{*10NADEKO, AB}

\author{
Department of Zoology, Faculty of Science, University of Lagos, Akoka, Lagos, Nigeria. \\ aonaddeko@unilag.edu.ng/onadeko2002@yahoo.com
}

\begin{abstract}
Anuran species diversity and abundance were evaluated in different farming status of cocoa plantation in Ore, Ondo State, Nigeria. Applying the combination of visual encounter survey (VES) and acoustical survey (AES), the different farms surveyed were categorized as; 1) pure cocoa farms with pesticides applied (PCWP); 2) pure cocoa farms without pesticides application; 3 ) intercropped cocoa farms with pesticides applied (ICWP); and 4) intercropped cocoa farms without pesticides application (ICNP). The surrounding primary/secondary forest (PSFV) was sampled applying the transect method. A mean total of $690 \pm 2.6$ anurans belonging to 28 species, 14 genera and 9 families were recorded during the study. Out of these, 10,19, 17, 22 and 26 species were recorded respectively from PCWP, PCNP, ICWP, ICNP and PSFV. The anuran species richness was significantly different between the different cocoa plantation status and the forest sites $\left(\mathrm{F}_{4,10}=20.55, \mathrm{P}<\right.$ $0.01)$. The highest mean number of individuals $(190 \pm 9.5)$ was observed at ICNP followed by PSFV (183 \pm 5.7$)$, while the least was at PCWP (77 \pm 8.0$)$. There was also significant difference $\left(\mathrm{F}_{4,10}=150.48, \mathrm{P}<0.01\right)$ between the abundance of anuran species at the various sites. Diversity indices (Shannon and Margalef) showed that the forest sites had the greatest (3.204 and 4.799) respectively while the pesticide using pure cocoa farms had the least (1.853 and 2.072). Generally, the result of the study clearly indicated that pesticide use cocoa farms were significantly lower compared to other sites. Farmers are encouraged to engage in intercropping (polyculture) especially with food and economic crops in a biodiversity friendly manner which could have similar characteristics of a natural ecosystem, thereby enhancing the biological diversity of agro-ecosystems. () JASEM

http://dx.doi.org/10.4314/jasem.v20i1.2
\end{abstract}

KEYWORDS: Anuran, cocoa, pesticides, intercropped, biological diversity and agro-ecosystems

Introduction

Nigeria is situated in the Guinea forest region of West Africa. This biodiversity hotspot region encompasses all of the lowland forests of political West Africa, stretching from Guinea and Sierra Leone eastward to the Sanaga River in Cameroun (www.cepf.net/where_wework/regions/africa/guinea $\mathrm{n} \_$forest). In this region logging, mining, hunting, unsustainable farming practices and human population growths are placing extreme stress on the forests which are threatening biological species. Presently this region is seriously threatened by deforestation, forest degradation and fragmentation (Bakarr et al., 2001; Beier et al., 2002; Hillers et al., 2008).

In Nigeria, about $65.2 \%$ of the vegetation has been lost to agricultural practices and only $4.9 \%$ are undisturbed, mangrove and montane forests (www.fao.org). NEST (1991), described the plant cover of the country as a patchwork of farmlands, plantations and secondary vegetation at varying stages of regrowth and maturity.

Cocoa (Theobroma cacao) is an important cash crop in Nigeria (Taphee et al., 2015) which was introduced in 1887 from the Amazon basin in South America (Ayoride, 1966). Presently Nigeria is the fourth leading exporter of cocoa in the world after Ivory Coast, Indonesia and Ghana (Cadoni, 2013). There are over 500,000 cocoa farmers engaged in cocoa production in Nigeria, producing more than 200,000 tons of cocoa per year from over 600,000 hectres of land. Over $50 \%$ of this quantity is produced in Ondo State alone with substantial quantities produced in Oyo, Ogun and Osun States (Taphee et al., 2015). Western Nigeria remains the predominant cocoa zone accounting for $94 \%$ of Nigeria's output (Ojo, 2003). The contributions of cocoa to the nation's economic development are vast and have been reported by many authors (Olayide, 1969; Folayan et al., 2006). Therefore agriculture has continued to play a dominant role in the provision of 
food, raw materials for industries, employment for the majority and foreign earnings which are used in financing development activities particularly the permanent crops such as cocoa (Fadipe et al., 2012).

However, agricultural practices such as. cocoa agroecosystems results in habitat loss, degradation, fragmentation and the creation of monoculture habitats which does not support anuran diversity. Habitat loss lowers anuran species diversity by reducing natural habitats (Cushman, 2006), and increasing population isolations (Arens et al., 2007), inbreeding (Anderson et al., 2004), edge effects (Urbina-Cardona et al., 2006) and discontinuity between terrestrial and aquatic habitats (Becker et al., 2010).

Also exacerbating the loss of biological diversity in the agro-ecosystems is the use of chemical control methods. Production and revenues from cocoa could be substantially higher if the plants were not confronted with strong parasitic pressures, diseases and insect pests (Mahob et al., 2014). Inorder to achieve this desire, farmers are engaged in the use of pesticides that reduces parasitic pressures to acceptable levels (Tadu et al., 2013).

Information on the effect of cocoa agro-ecosystems (modified habitats) on anurans is lacking, especially taking into cognizance the different status of the cocoa plantation. Due to the manipulation and caretaking of the various farms by the farmers, 1) some farms are grown with the use of herbicides and pesticides regularly, 2) some with the irregular use of herbicides and pesticides, 3) those farms grown and intercropped with cola nut, banana, plantain and cassava food crops with the regular use of herbicides and pesticides and 4) those farms grown and intercropped with other food crops without the regular use of chemical control. This study aims to access the effects of these different cocoa plantations on the diversity, abundance and distribution of the anuran community.

\section{MATERIALS AND METHODS}

Study Sites: The study took place at a farming location about $15 \mathrm{~km}$ from Ore town in Ondo State (Figure 1). There were several cocoa farms located among primary/secondary forests vegetation. Two farms each were selected based on the usage of chemical control methods and type of planting (nonintercropping or intercropping). These categories were;

1) those using herbicides (such as Foler 525, Gramoxone) and insecticides (such as Cocostar 210EC, Basudin 600EC) regularly. In these farms, the farmers planted only cocoa plants and applied the chemical control method at least twice a year. These farms were given the name 'Pure Cocoa With Pesticide' (PCWP).

2) those irregularly using chemical methods of control (had not been applied for the past $\geq 5$ years). The farmers in this category irregularly apply the chemical control method at least once every two or three years. But prior to the sampling, it was established that the farmer had not applied the control method for the past five years. These farms were given the name 'Pure Cocoa No Pesticide' (PCNP).

3) cocoa farms grown and intercropped with cola nut (Cola nitida), banana (Musa sapentium), plantain (Musa paradisiaca) and cassava (Manihot esculenta) using herbicides and insecticides regularly. In these farms food crops were planted among the cocoa plants. Farmers ate the produce from these food crops directly and some were sold to gain income. Chemical control method was applied at least twice a year. These farms were given the name 'Intercropped Cocoa With Pesticide' (ICWP).

4) cocoa farms grown and intercropped with food crops in which chemical control method have not been applied for over $\geq 5$ years. This was given the name 'Intercropped Cocoa No Pesticide' (ICNP).

The primary/secondary forest surrounding the various farms was used as control (PSFV). The GPS of the study sites are shown on Table 1 and parts of the sites are shown on Plates 1-3. 


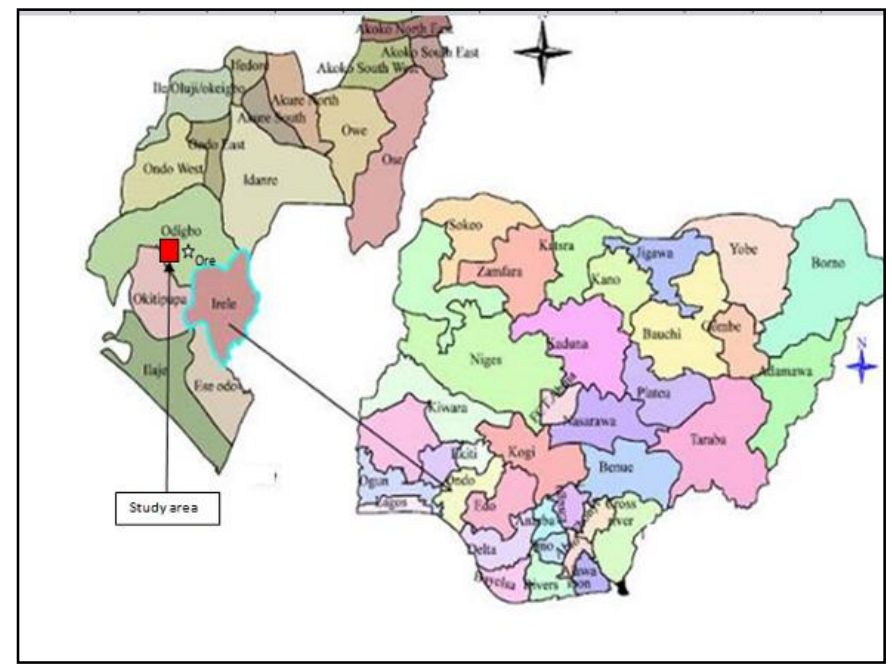

Fig.1. Map of Ondo State (projected from map of Nigeria) showing study area near Ore, Odigbo Local Government. (Map adapted from www.google.com.ng)

Table 1. Short habitat characterization and GPS location of the study sites.

\begin{tabular}{clcc}
\hline Study Site & \multicolumn{1}{c}{ Short habitat status characterization } & Acronym & GPS Location \\
\hline & & PCWP & $6.797936 \mathrm{~N}, 4.836292 \mathrm{E}$ \\
$\mathbf{1 A}$ & Pure cocoa farm with the use of pesticides & PCWP & $6.789754 \mathrm{~N}, 4.811573 \mathrm{E}$ \\
$\mathbf{1 B}$ & Pure cocoa farm with the use of pesticides & PCNP & $6.819754 \mathrm{~N}, 4.786854 \mathrm{E}$ \\
$\mathbf{2 A}$ & Pure cocoa farm without the use of pesticides & PCNP & $6.808845 \mathrm{~N}, 4.825306 \mathrm{E}$ \\
$\mathbf{2 B}$ & Pure cocoa farm without the use of pesticides & ICWP & $6.784300 \mathrm{~N}, 4.836292 \mathrm{E}$ \\
$\mathbf{3 A}$ & Intercropped cocoa farm with the use of pesticides & ICWP & $6.781572 \mathrm{~N}, 4.808827 \mathrm{E}$ \\
$\mathbf{3 B}$ & Intercropped cocoa farm with the use of pesticides & ICNP & $6.778845 \mathrm{~N}, 4.844532 \mathrm{E}$ \\
$\mathbf{4 A}$ & Intercropped cocoa farm without the use of pesticides & ICNP & $6.800663 \mathrm{~N}, 4.811573 \mathrm{E}$ \\
$\mathbf{4 B}$ & Intercropped cocoa farm without the use of pesticides & PSFV & $6.776117 \mathrm{~N}, 4.797840 \mathrm{E}$ \\
$\mathbf{5 A}$ & Primary/Secondary forest vegetation & PSFV & $6.814299 \mathrm{~N}, 4.792347 \mathrm{E}$ \\
$\mathbf{5 B}$ & Primary/Secondary forest vegetation & & \\
\end{tabular}

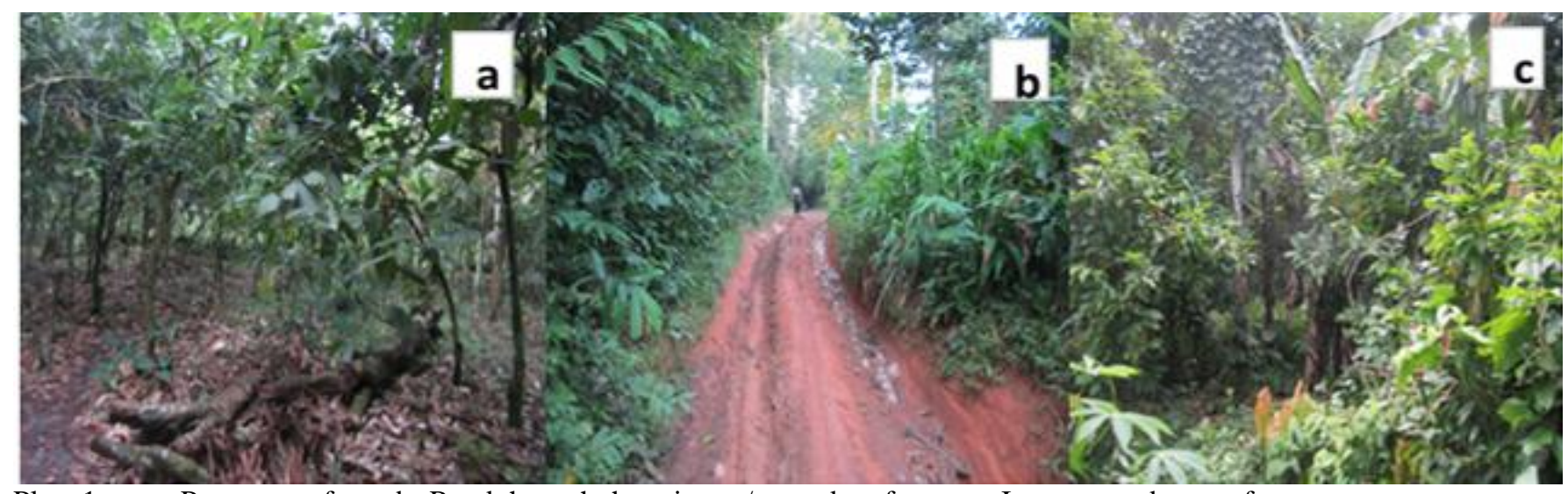

Plate 1a-c. a- Pure cocoa farm; b- Road through the primary/secondary forest; c- Intercropped cocoa farm

Sampling Technique: The study was conducted during the rainy season (June-August) for three consecutive years (2012-2014). The sites were visited and sampled for one week in each month giving a total of 21 days yearly. Each cocoa plantation had a quadrate of $90 \times 90 \mathrm{~m}$ installed using red tapes to demarcate the study area. As much as possible all microhabitats utilized by the anurans were incorporated in the quadrate. A combination of visual encounter survey (VES) and acoustical survey (AES) 
(Rodel and Ernest, 2004) were conducted in each quadrate. This was done in order to estimate anuran diversity and abundance of each study area.

Due to the nature of the forest (some area being impenetrable), the transect sampling method was applied (Rodel and Ernest, 2004). There were a total of five transects, each measuring $100 \times 5 \mathrm{~m}$. Some of the foot paths used by hunters and farmers were partially used as transects. All anuran species observed on the transects and $5 \mathrm{~m}$ on each side were recorded. The transects were patrolled between 0500 and $0700 \mathrm{hr}$ in the morning and 1800 to $2000 \mathrm{hr}$ in the evening. All microhabitats were thoroughly searched by three individuals (researcher and two field assistants). To avoid duplication of results, toe clipping of individuals were done according to Donnelly et al., (1994). Identification and Statistical Analysis

Anuran species were identified to the genus and species level using literature published by Rodel (2000) and juveniles were identified by literature published by Channing et al., (2012). Individuals caught were recorded and immediately released. However some were used as voucher specimens.

Descriptive statistics was performed using SPSS ver. 16 (SPSS 2007) and the one-way analysis of variance (ANOVA) was used to ascertain if significant difference exists between the different status cocoa farms regarding species diversity and abundance. The Duncan's Multiple Range (DMR) test analysis was applied to locate significant difference between means of the various sites. The ecological indices were obtained using the PAST (ver. 2.17) programme.

\section{RESULTS AND DISCUSSION}

A mean total of $690 \pm 2.6$ anurans belonging to 28 species, 14 genera and 9 families were recorded during the study. Out of these, 10, 19, 17, 22 and 26 species were recorded respectively from PCWP, PCNP, ICWP, ICNP and PSFV (Table 2 and Figure 2 ). The forest sites had the greatest number of species followed by the cocoa farm intercropped with food crops not utilizing pesticides, while the least number was observed in pure cocoa farms applying chemical control methods. The anuran species richness was significantly different between the different cocoa plantation status and the forest sites $\left(\mathrm{F}_{4,10}=20.55, \mathrm{P}<\right.$ 0.01). Multiple comparisons of means using the Duncan's Multiple Range (DMR) test analysis $\left(\mathrm{PCWP}^{\mathrm{a}}, \mathrm{PCNP}^{\mathrm{b}}, \mathrm{ICWP}^{\mathrm{c}}, \mathrm{ICNP}^{\mathrm{cd}}, \mathrm{PSFV}^{\mathrm{d}}\right.$ ) showed that forest and cocoa farm intercropped with food crops not applying pesticide were not significantly different

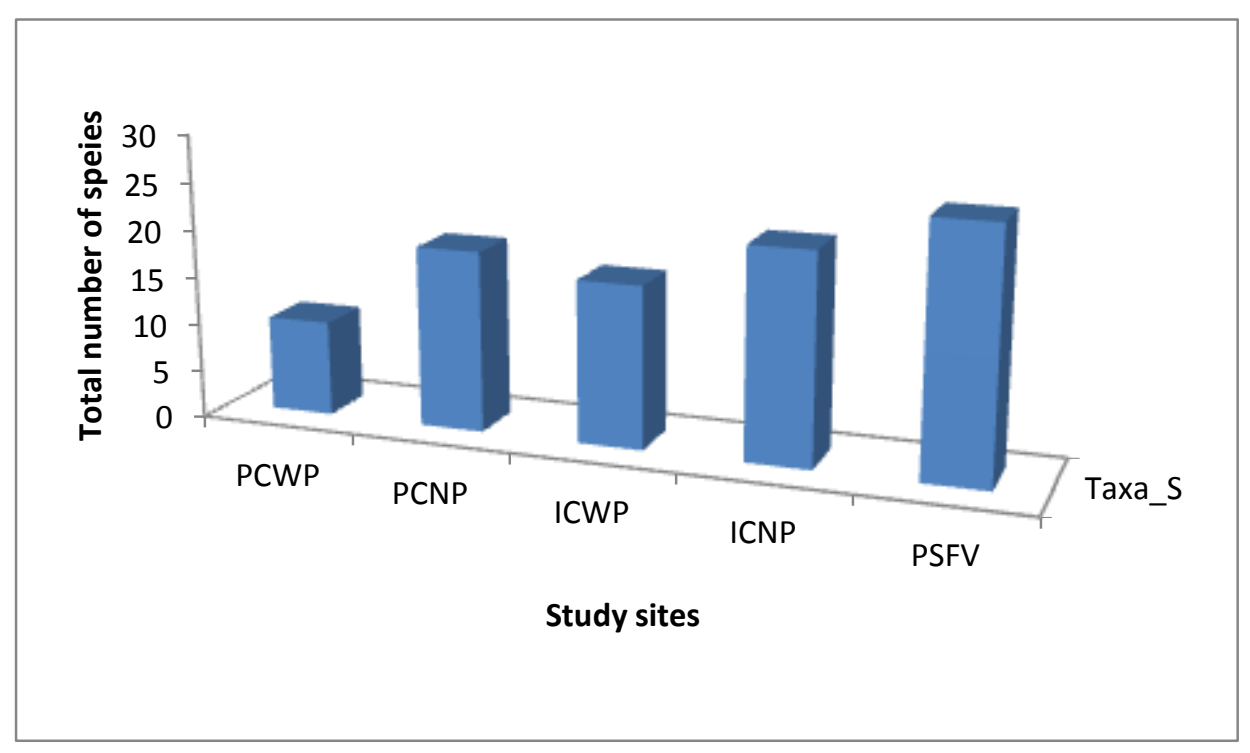

Fig. 2. Total number of species across sites

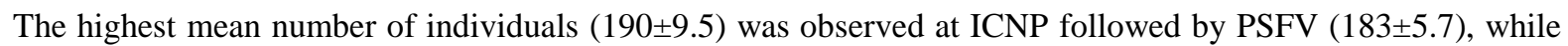
the least was at PCWP (77 \pm 8.0$)$. See Figure 3. Non-pesticide treated PCNP sites had a greater abundance $(133 \pm 6.4)$ than pesticide treated sites of PCWP (77 \pm 8.0$)$ and ICWP $(107 \pm 3.1)$. There was also significant

$$
\text { * } \mathrm{ONADEKO}, \mathrm{AB}
$$


difference $\left(\mathrm{F}_{4,10}=150.48, \mathrm{P}<0.01\right)$ between the abundance of anuran species at the various sites. Multiple comparisons of means using the Duncan's Multiple Range (DMR) test analysis $\left(\mathrm{PCWP}^{\mathrm{a}}, \mathrm{PCNP}^{\mathrm{b}}, \mathrm{ICWP}^{\mathrm{c}}\right.$, ICNP $^{\mathrm{d}}, \mathrm{PSFV}^{\mathrm{d}}$ ) also showed that forest and cocoa farm intercropped with food crops not applying pesticide were not significantly different.

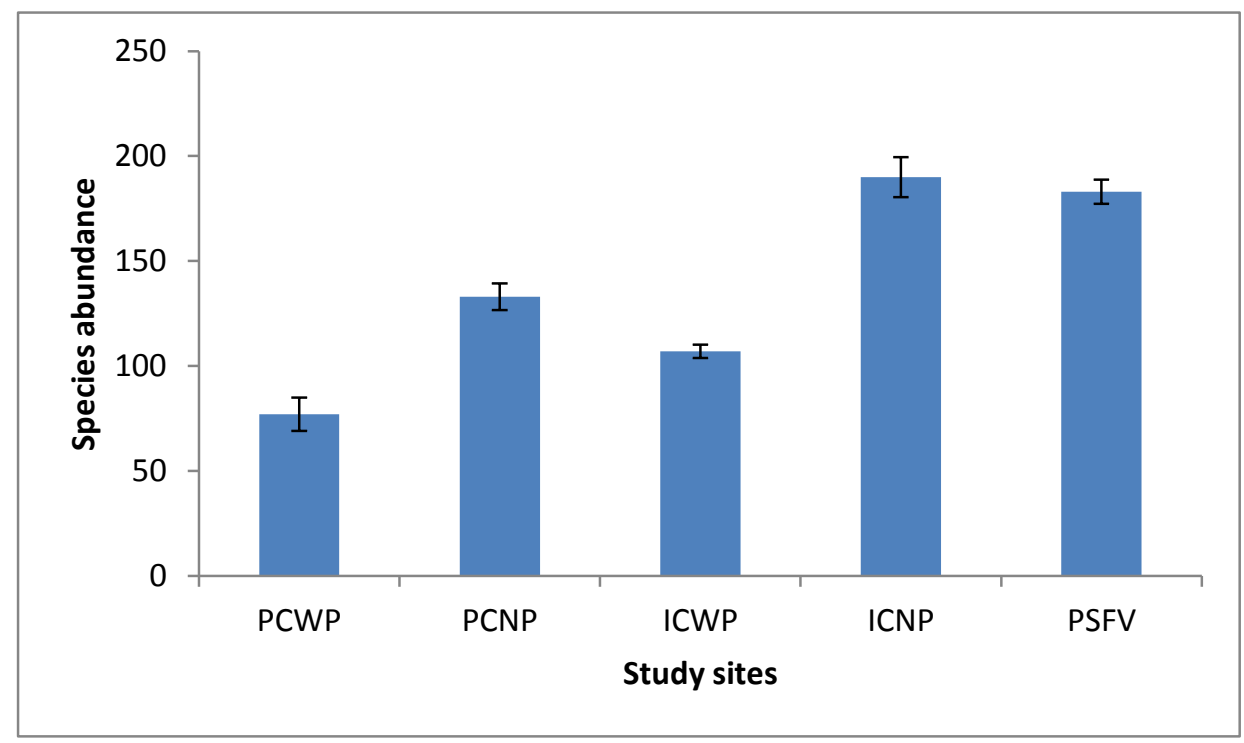

Fig. 3. Mean abundance of individuals across sites

Both diversity indices (Shannon and Margalef) showed that the forest sites had the greatest (3.204 and 4.799) respectively while the pesticide using pure cocoa farms had the least (1.853 and 2.072) (Figure 4). Similarly, the evenness and equitability indices were highest in the forest sites but now least in the pure cocoa plantation not applying the use of chemical control methods (Figure 5). Some of the anuran species observed in the survey are shown on Plate 2a-d.

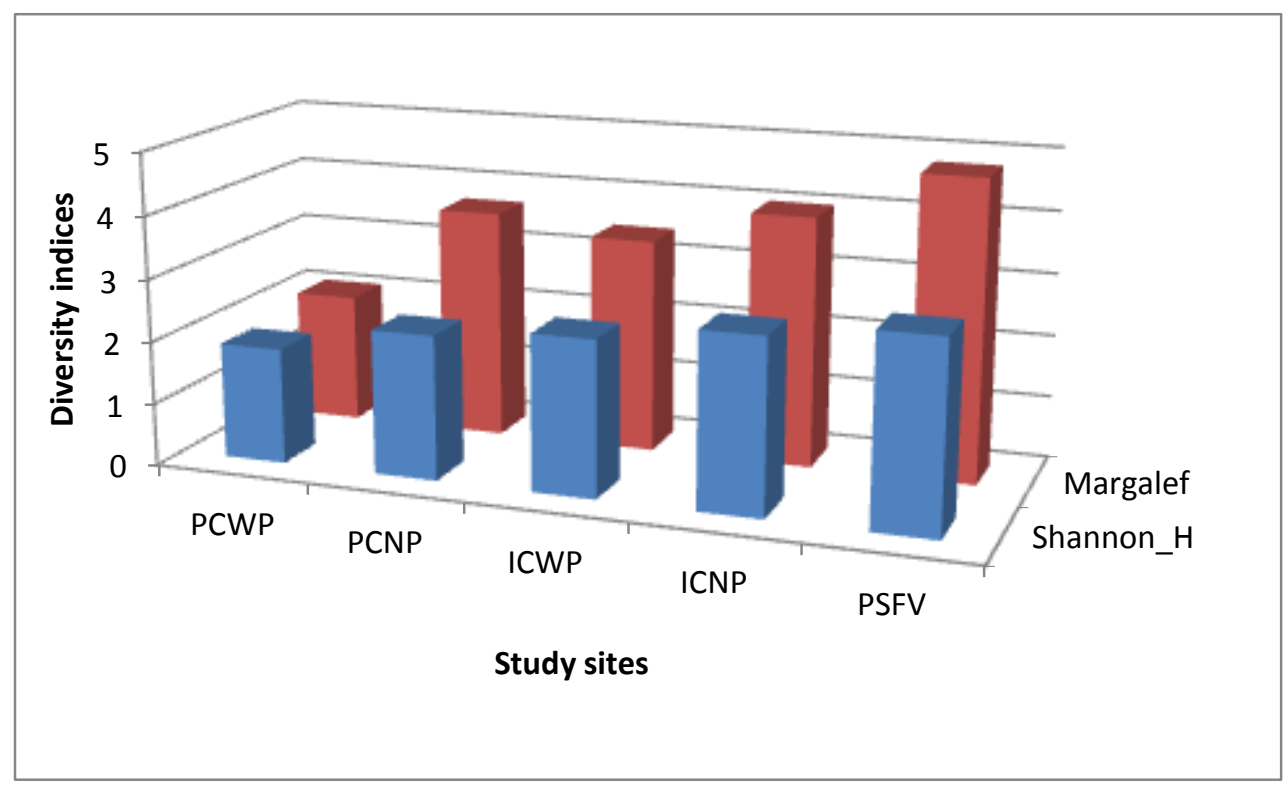

Fig. 4. Diversity indices across sites 


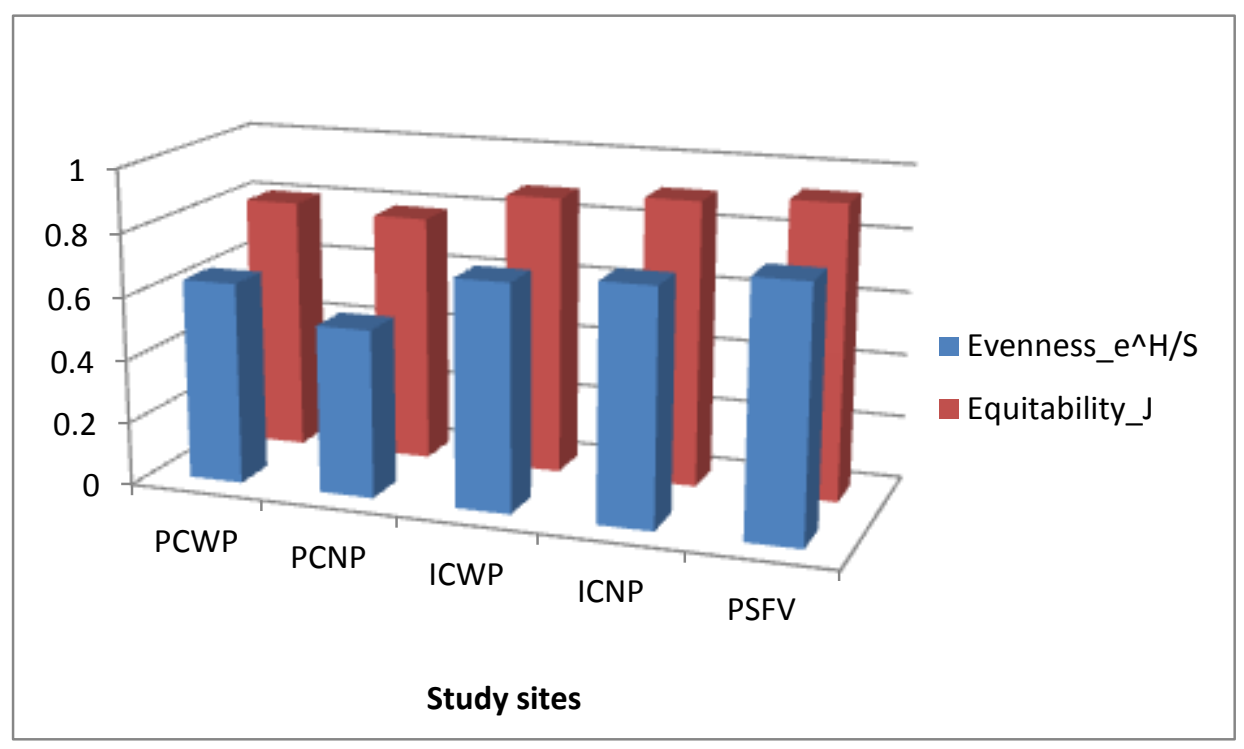

Fig. 5. Evenness and equitability indices across sites

Table 2. Mean abundance of anuran species in four different types of cocoa farms and control sites.

\begin{tabular}{|c|c|c|c|c|c|}
\hline Anuran Species & PCWP & PCNP & ICWP & ICNP & PSFV \\
\hline \multicolumn{6}{|l|}{ PIPIDAE } \\
\hline Xenopus muelleri & & $2 \pm 2.3$ & $4 \pm 1.5$ & $10 \pm 1.7$ & $6 \pm 2.0$ \\
\hline \multicolumn{6}{|l|}{ HEMISOTIDAE } \\
\hline $\begin{array}{l}\text { Hemisus marmoratus } \\
\text { BUFONIDAE }\end{array}$ & \multicolumn{4}{|c|}{ BUFONIDAE } & $4 \pm 1.5$ \\
\hline Amietophrynus regularis & $21 \pm 3.0$ & $32 \pm 3.2$ & $18 \pm 2.0$ & $26 \pm 4.0$ & $12 \pm 2.1$ \\
\hline A. maculatus & $11 \pm 3.1$ & $18 \pm 2.5$ & $9 \pm 0.6$ & $16 \pm 3.5$ & $8 \pm 2.0$ \\
\hline Nectophryne afra & & & & & $4 \pm 2.9$ \\
\hline \multicolumn{6}{|l|}{ DICROGLOSSIDAE } \\
\hline Hoplobatrachus occipitalis & & $2 \pm 1.0$ & $6 \pm 2.6$ & $11 \pm 4.4$ & $6 \pm 2.0$ \\
\hline \multicolumn{6}{|l|}{ RANIDAE } \\
\hline Hydrophylax albolabris & & & & & $14 \pm 3.6$ \\
\hline H. galamensis & & $1 \pm 0.6$ & & $1 \pm 0.6$ & $4 \pm 1.7$ \\
\hline & \multicolumn{3}{|c|}{ PTYCHADENIDAE } & $2 \pm 1.2$ & $2 \pm 0.6$ \\
\hline Ptychadena pumilio & $22 \pm 3.2$ & $28 \pm 4.0$ & $18 \pm 0.6$ & $21 \pm 7.5$ & $14 \pm 0.6$ \\
\hline Ptychadena oxyrhynchus & $6 \pm 2.1$ & $4 \pm 2.6$ & $4 \pm 0.6$ & $6 \pm 2.5$ & $2 \pm 1.0$ \\
\hline Ptychadena bibroni & & $1 \pm 1.2$ & & $2 \pm 1.0$ & \\
\hline Ptychadena mascareniensis & $3 \pm 0.0$ & $6 \pm 1.2$ & $8 \pm 3.0$ & $8 \pm 1.0$ & $4 \pm 2.1$ \\
\hline Ptychadena longirostris & & $3 \pm 0.6$ & $2 \pm 1.5$ & $4 \pm 1.2$ & $1 \pm 1.0$ \\
\hline $\begin{array}{l}\text { Ptychadena aequiplicata } \\
\text { PHRYNOBATRACHIDAE }\end{array}$ & & & & & $6 \pm 2.6$ \\
\hline $\begin{array}{l}\text { Phrynobatrachus accraensis } \\
\text { Phrynobatrachus francisci }\end{array}$ & $8 \pm 2.0$ & $14 \pm 1.0$ & $\begin{array}{l}8 \pm 1.7 \\
1 \pm 1.0\end{array}$ & $12 \pm 2.6$ & $2 \pm 0.6$ \\
\hline Phrynobatrachus plicatus & & $2 \pm 0.6$ & & $3 \pm 1.7$ & $5 \pm 1.2$ \\
\hline $\begin{array}{l}\text { Phrynobatrachus sp } \\
\text { ARTHROLEPTIDAE }\end{array}$ & & & & $1 \pm 0.6$ & $2 \pm 1.0$ \\
\hline Arthroleptis variabilis & $1 \pm 0.0$ & $6 \pm 3.5$ & $2 \pm 0.6$ & $8 \pm 1.2$ & $19 \pm 5.5$ \\
\hline Leptopelis viridis & $2 \pm 1.2$ & $6 \pm 2.1$ & $14 \pm 4.2$ & $20 \pm 4.6$ & $18 \pm 4.6$ \\
\hline Leptopelis boulengeri & & $1 \pm 1.5$ & $1 \pm 1.0$ & $3 \pm 1.5$ & $9 \pm 3.5$ \\
\hline
\end{tabular}




\begin{tabular}{|c|c|c|c|c|c|}
\hline \multicolumn{6}{|l|}{ HYPEROLIIDAE } \\
\hline Afrixalus dorsalis & $1 \pm 1.2$ & $2 \pm 0.6$ & $3 \pm 1.5$ & $8 \pm 2.3$ & $12 \pm 4.5$ \\
\hline Hyperolius nasutus & & & $2 \pm 2.3$ & $8 \pm 0.6$ & $6 \pm 1.2$ \\
\hline Hyperolius-fusciventris burtoni & $2 \pm 0.0$ & $3 \pm 1.2$ & $5 \pm 2.3$ & $12 \pm 1.6$ & $8 \pm 0.6$ \\
\hline Hyperolius guttulatus & & & & & $9 \pm 3.6$ \\
\hline $\begin{array}{l}\text { Hyperolius concolour } \\
\text { ibadanensis }\end{array}$ & & $1 \pm 0.6$ & $2 \pm 1.5$ & $6 \pm 1.5$ & $4 \pm 0.0$ \\
\hline Phlyctimantis boulengeri & & & & & $2 \pm 1.5$ \\
\hline
\end{tabular}

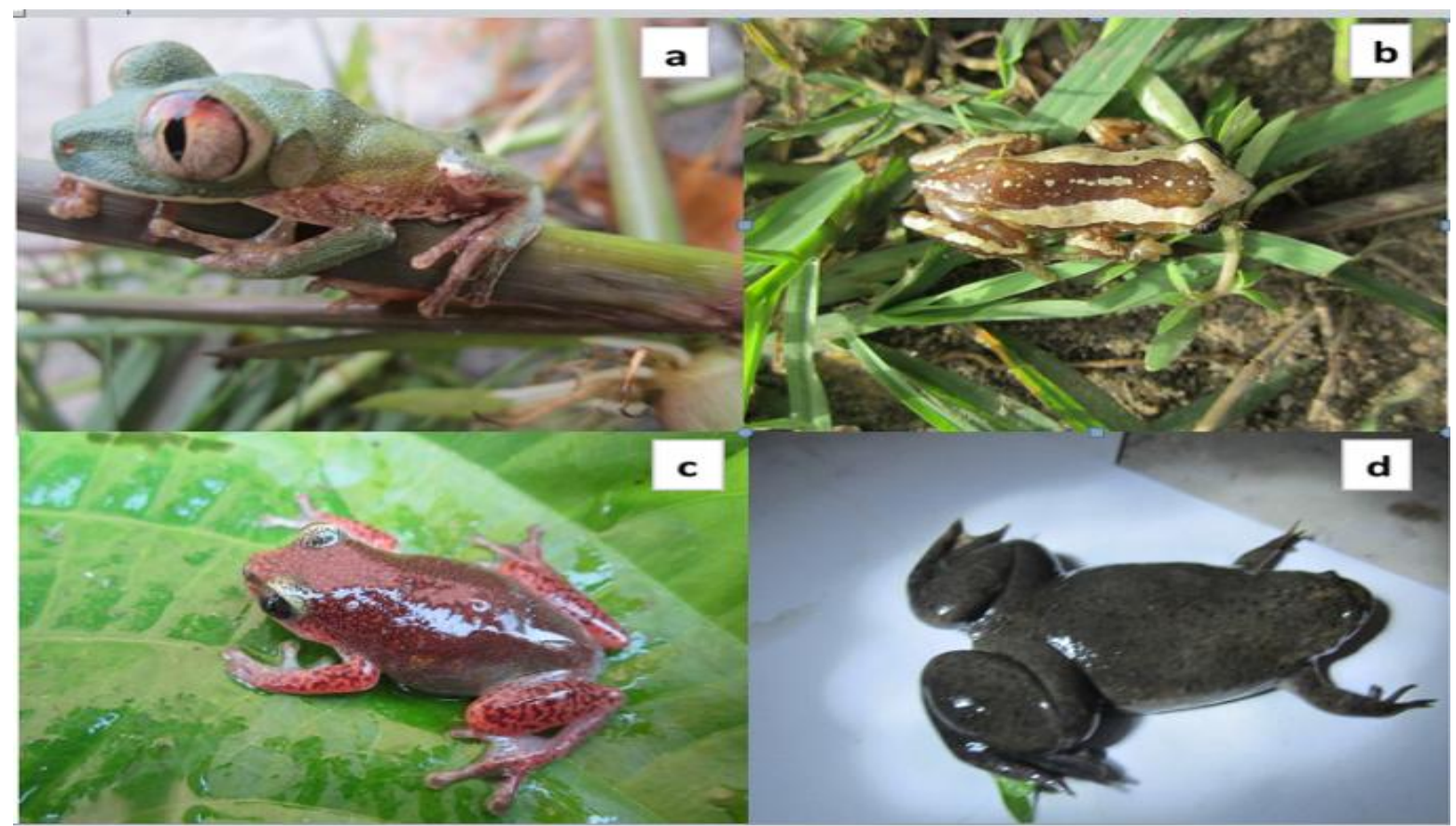

Plate 2a-d. Anuran species a- Leptopelis boulengeri; b- Afrixalus dorsalis; c- Hyperolius guttulatus; d-Xenopus muelleri

This study attempts to reveal the effect of different cocoa plantation farming types on the diversity and abundance on anuran communities. Clearly, significant difference occurred between sites where pesticides were applied. Pesticides are used to control pests and diseases thereby enhancing cocoa production. The importance of cocoa in the economy of Nigeria cannot be overemphasized, as its popularity and earnings has made this sub-sector an area of interest to policy makers especially due to its contributions to total Gross Domestic Product (GDP) and being the highest foreign exchange earner among all agricultural commodities (Oyekale et al., 2009). But despite the importance of the use of pesticides in enhancing cocoa production, results show it has a negative effect on anuran diversity and abundance. There was a significant reduction in anuran population at sites where pesticides were applied. This signifies the negative effect of these chemicals on the existence of these species. According to Bruhl et al., (2013), the negative effects of pesticide are probable since their skin is highly permeable to allow gas, water and electrolyte exchange with the environment. The dermal uptake processes of chemicals has shown to be two orders of magnitude faster than in mammals (Quaranta et al., 2009), suggesting that for terrestrial amphibian life stages present in crop fields, pesticide uptake through the skin might represent a likely exposure route (Bruhl et al., 2011). Also with a life cycle occurring both in the terrestrial and aquatic environments, with migrations to and from spawning waters, anurans are exposed to toxicants in both environments (Fryday et al., 2012).

Pesticides may hamper growth and development, and they may cause developmental and behavioural abnormalities in amphibians (Sparling et al., 2000; Boone and Bridges, 2003). Sources of contaminants 
from pesticides may provoke stress response disrupting the endocrine system which could alter reproductive potentials of anurans (Hayes, 2000). Hayes et al., (2002) showed that the herbicide atrazine used commonly induced hermaphroditism and demascularized the larynges of exposed African clawed frog (Xenopus laevis) males. Therefore all these factors could lead to the decline of anuran population which was observed at the sites where pesticides were applied in this study.

From results it was observed that the forest sites (control) had the highest diversity of anuran species compared to the monoculture sites. About $18 \%$ of species were present only at the forest sites. Species composition often varies across different land use types and regimes and species that requires specific ecological conditions that are not available in modified land uses maybe more affected than others (Rathod \& Rathod, 2013). This may be true for forest species such as Phlyctimantis boulengeri, Hydrophylax albolabris, Nectophryne afra, and Ptychadena aequiplicata that were absent from the cocoa farming sites in this study.

In monoculture sites there has been reduction in the biodiversity of plants which also directly leads to animal species reduction. Wild ecosystems (e.g. forests) are diverse and contain wild population of plants and animals each with a unique adaptation to its environment. The monoculture system lacks this variability, hence reduces the diversity of species existing therein. Hence the reduction of species observed in the monoculture sites compared to the forest in this study. Similar observations were made by (Young et al., 2001; Green, 2003; Cushman, 2006) who revealed that the replacement of natural environments by man-made habitats is one of the major causes of change in population and community structure of amphibians around the world. Humaninduced impacts can influence amphibian population by modifying the physical structure of the habitat, the frequency and distribution of reproductive sites such as streams, lakes and temporary ponds (Metts et al., 2001).

From the multiple comparisons of means using the Duncan's Multiple Range (DMR) test, there was no significant difference between the forest site and the cocoa farm intercropped with food crops not applying pesticide. Intercropping (polyculture) increases the variability of plant species which directly affects the diversity of animal species. This gives somewhat a close resemblance to a natural ecosystem, enhancing the variability of organisms. Similar concept includes the plant shade system in which other fruiting and timber species are inserted between the cocoa plants to provide shade (Heinen, 1992). The provision of intercropped food crops among cocoa plants will probably enhance on the local level biodiversity in the tropical agricultural landscape.

The diversity, evenness and equitability indices were highest in the forest and intercropped cocoa farms not applying pesticides. This further buttress the fact that intercropping has a positive impact on biodiversity conservation. It is important that farmers engage in intercropping other food crops or economic crops with cocoa plants to enhance local biological diversity which would favour the existence of the anuran species.

Conclusion: With the conversion of most pristine habitats, agricultural land area is becoming one of the largest terrestrial biome existing today. Food and economic crops planted are expected to produce maximum yield, therefore the eradication of pests and diseases negatively affecting production and revenues are achieved by the application of pesticides. The negative environmental impacts of pesticides are tremendous as majority of the chemicals reach destinations other than their target species, affecting non-target species such as anurans. It is pertinent to note that reductions in the use of pesticides will greatly improve the biodiversity status of any crop plantation. Farmers are also encourage to engage in intercropping (polyculture) especially with native forest food and economic crops in a biodiversity friendly manner which could have similar characteristics of a natural ecosystem, thereby enhancing the biological diversity of agroecosystems.

\section{REFERENCES}

Anderson, L.W., Fog, K. and Damgaard, C. (2004). Habitat fragmentation causes bottlenecks and inbreeding in the European treefrog (Hyla arborea). Proc. Biol. Sci. 271: 1293-1302

Arens, P. (2007). Genetic population differentiation and connectivity among fragmented Moor frog (Rana arvalis) populations in The Netherlands. Landscape Ecol. 22: 1484-1500

Ayoride, J.A. (1966). Historical notes on the introduction and development of cocoa industry in Nigeria. Agricultural Journal. 3: 18-23

Bakarr, M., Bailey, B., Byler, D., Ham, R., Olivieri, S. and Omland, M. (2001). From the forest to the 
sea: biodiversity connections from Guinea to Togo, Conservation Priority-Setting Workshop, December 1999.-Washington D. C. (Conservation International), 78pp.

Becker, C.G., Fonseca, C.R., Haddad, C.F.B. and Prado, P.I. (2010). Habitat split as a cause of local population declines of amphibians with aquatic larvae. Conserv. Biol. 24: 287-294

Beier, P., Van Drielen, M. and Kankam, B.O. (2002). Avifauna collapse in West African forest fragments. Conservation Biology. 16: 1097-1111

Bone, M.O. and Bridges, C.M. (2003) A hierarchical approach in studying the effects of an insecticide on amphibians In: Linder, G., Sparling D.W. and Krest, S.K. eds. Multiple Stressors and Declining Amphibians Populations: Evolutionary Cause and Effects. Pensacola: Society of Environmental Toxicology and Chemistry Press. Pp 265-270

Bruhl, C.A., Pieper, S. and Weber, B. (2011). Amphibians at Risk? Suceptability of terrestrial amphibian life stages to pesticides. Environ. Toxcol. Chem. 30: 2465-2472

Bruhl, C.A., Schmidt, T., Pieper, S. and Alscher, A. (2013). Terrestrial pesticide exposure of amphibians: An underestimated cause of global decline? Sci. Rep. 3: 1135

Cadoni, P. (2013). Analysis of incentives and disincentives for cocoa in Nigeria. Technical notes series, Monitoring African Food and Agricultural Polices (MAFAP), FAO, Rome. $33 \mathrm{pp}$

Channing, A., Rodel, M.O. and Channing, J. (2012). Tadpoles of Africa: The biology and identification of all known tadpoles in subSaharan Africa. Edition Chimaira, Frankfurt am Main

Cushman, S.A. (2006). Effects of habitat loss and fragmentation on amphibians: a review and prospectus. Biological Conservation. 128(2): 231-240

Donnelly, M. Chen, A. Waston, C., and Watkins, G. (1994). Herpetofauna of the Iwokrama Forest, Iwokrama http://www.iwokrama.org/Herpetofaunal of the Iwokrama Forest.pdf.
Fadipe, B.G., Adenuga, A.H. and Ilori, T.E. (2012). Economic analysis of cocoa production in Oyo State, Nigeria. Nigerian Journal of Agriculture, Food and Environment. 8(4): 58-63

Folayan, J.A., Daramola, G.A. and Oguntade, A.E. (2006). Structure and performance evaluation of Cocoa Marketing Institutions in South-Western Nigeria: An economic analysis. Journal of Food, Agriculture and Environment. 4(2): 123-128

Fryday, S and Thompson, H. (2012). Toxicity of pesticides to aquatic and terrestrial life stages of amphibians and occurrence, habitat use and exposure of amphibian species in agricultural environments. EFSA Supporting Publications: EN-343 pp.348

Green, D.M. (2003). The ecology of extinction: population fluctuation and decline in amphibians. Biological Conservation. 111(3): $331-343$

Hayes, T.B. (2000). Endocrine disruption in amphibians. Ecotoxicology of amphibians and reptiles. (ed. By D.W. Sparling, G. Linder and C. Bishop), pp 53-593, SETAC Press, Pensacola, FL.

Hayes, T., Haston, K., Tsui, M., Hoang, A, Haeffele, C. and Vonk, A. (2002). Herbicides: feminization of male frogs in the wild. Nature. 419(6910): 895-896

Heinen, J.T. (1992). Comparisons of the leaf litter herpetofauna in abandoned cacao plantations and primary rain forest in Costa Rica: Some implications for faunal restoration. Biotropica 24(3): 431-439.

Hillers, A., Veith, M. and Rodel, M.O. (2008). Effects of forest fragmentation and habitat degradation on West African leaf-litter frogs. Conserv. Biol. 22: 762-772

Mahob, R.J., Ndoumbe-Nkeng, M., Ten Hoppen, G.M., Dibog, L., Nyasse, S., Rutherford, M., Mbenoun., M., Babin, R., Mbang, A., Yede, A and Bilong, C.F. (2014). Pesticides use in cocoa sector in Cameroon: characterization of supply source, nature of active ingredients, fashion and reasons for their utilization. International Journal of Biological and Chemical Sciences. 8(5): 1976-1989

Metts, BB.S., Lanham, J.D. and Russel, K.R. (2001). Evaluation of herpetofaunal communities on 
upland streams and beaver-impounded streams in the upper Piedmont of South Carolina. American Mainland Naturalist. 145(1): 54-65

NEST (Nigerian Environmental Study/Action Team) (1991) Nigeria's Threatened Environment-A National Profile. Intec Printers Limited, Ibadan 288pp

Olayide, S.O. (1969). Some estimates of supply and demand elasticities for selected commodities in Nigeria's foreign trade. Journal of Business and Social Studies. 1(9): 176-193

Ojo, S.O. (2003). Productivity and technical efficiency of poultry eggs production in Nigeria. International Journal of Poulty Science. 2(6): 459-464

Oyekale, A.S., Bolaji, M.B. and Olowa, O.W. (2009). The effects of Climate Change on cocoa production and vulnerability assessment in Nigeria. Agricultural Journal 4: 77-85

Quaranta, A., Bellantuono, V., Cassano, G. and Lippe, C. (2009). Why amphibians are more sensitive than mammals to xenobiotics. Plos One 4(11): e7699. doi: 10.1371/journal.pone.0007699

Rathod, S. and Rathod, P. (2013). Amphibian communities in three different coffee plantation regimes in the Western Ghats, India. Journal of Threatened Taxa. 5(9): 4404-4413

Rodel, M.O. (2000). Herpetofauna of West Africa. Vol. I. Amphibians of the West African Savanna. Edition Chimaira, Frankfurt am Main. 332pp.

Rodel, M.O. and Ernst, R. (2004). Measuring and Monitoring Amphibian Diversity in Tropical Forests. I. An Evulation of Methods with Recommendation for Standardization. Ecotropica 10: 1-14.
Sparling, D.W., Fellers, G.M. and McConnells, L.L. (2000). Pesticides and amphibian population declines in California, USA. Environmental Toxicology and Chemistry. 20(7): 1591-1595

Tadu, Z., Dejieto-Lordon, C., Babin, R., Yede, Messop-Youbi, E.B., Fomena, A. (2013). Influence of insecticide treated on ant diversity in tropical agroforestry system: Some aspect of the recolonization process. Int. J. Biodivers. Conserv., 5(12): 832-844

Taphee, B.G., Musa, Y.H. and Vosanka, I.P. (2015). Economic efficiency of cocoa production in Gashaka Local Government Area, Taraba State, Nigeria. Mediterranean Journal of Social Sciences. 6: 570-576

Urbina-Cardona, J.N., Olivares-Perez, M. and Reynoso, V.H. (2006). Herpetofauna diversity and microenvironment correlates across a pasture-edge-interior ecotone in tropical rainforest fragments in the Los Tuxtles Biosphere Reserve of Veracruz, Mexico. Biol. Conserv. 132: 61-75

Young, B.E., Lips, K.R., Reaser, J.K., Ibanez, R., Salas, A.W., Cedeno, J.R., Coloma, L.A., Ron, S., La Marca, E., Meyer, J.R., Munoz, A., Bolanos, F., Chaves, G. and Romo, D. (2001). Population declines and priorties for amphibian conservation in Latin America. Conservation Biology. 15(5): 1213-1223

Web References www.cepf.net/where wework/regions/africa/guinean forest

www.fao.org 